\title{
Capítulo VI Prácticas Comerciales y representaciones en el artesano de René Mardellat
}

\author{
Chapter VI Commercial Practices and representations in the artisan of René Mardellat
}

\section{María P. Fernández-Cuevas ${ }^{a}$}

\begin{abstract}
:
Mardellat, raises as main ideas, the realization of a research that establishes a general way to know the social representation that the French artisan has in the field of commercial management and its economic implications for its safeguard and development in the current context.
\end{abstract}

\section{Keywords:}

Social representations, traditions, economic reality

\section{Resumen:}

Mardellat, plantea como principales ideas, la realización de una investigación que establece de manera general el conocer la representación social que tiene el artesano francés en el terreno de la gestión comercial y sus implicaciones económicas para su salvaguarda y desarrollo en el contexto actual.

\section{Palabras Clave:}

Representaciones sociales, tradiciones, realidad económica

\section{Introducción}

En el capítulo sexto del texto en comento, denominado Prácticas Comerciales y representaciones en el artesano, el autor Mardellat, plantea como principales ideas, la realización de una investigación que establece de manera general, el conocer la representación social que tiene el artesano francés en el terreno de la gestión comercial y sus implicaciones económicas para su salvaguarda y desarrollo en el contexto actual.

Mardellat, expone el planteamiento en torno al cual gira la investigación, su historia y tradiciones en las que se centra el objeto de estudio, sus objetivos, metodología así como la óptica desde la cual se pretende su estudio, siendo éste el de las representaciones sociales.

El planteamiento es que los artesanos franceses, no perciben la realidad económica tal como es, siendo necesario que la imagen del artesano y su realidad sea decodificada y reapropiada lo cual conduciría a un sistema individualizado, $y$ al mismo tiempo compartido $y$ elaborado en colectivo.

El autor René, rechaza tajantemente la entrada de cualquier esquema mecanicista en el que la representación sería el elemento causal explicativo y único de comportamiento del artesano y establece que la relación que tiene el sujeto con el mundo exterior es mediatizado por nuestras representaciones sociales, que tratan y filtran las informaciones que nos llegan y que nos proporcionan un punto de partida y referente válido para comportarnos el cual justificar nuestros actos.

Por ello indica Mardellat, el trabajo se centra en la representación de sí mismo de su status y del grupo al que pertenece, tratando de ubicar la imagen que tienen los artesanos de sí mismos así en relación con la competencia con el otro; la representación del entorno competitivo en cuanto a la identificación de los rivales y la prospectiva a nivel de sus fortalezas y sus debilidades; 
la representación del cliente y por último el sistema de valores de los artesanos.

Como objetivos de investigación se plantean el entender la naturaleza de las reticencias de los artesanos en adoptar comportamientos comerciales mejor adaptados a la realidad de su mercado.

En cuanto a su metodología, en primer término se elige a la población de artesanos situación que se da a partir del posicionamiento económico y comercial de las profesiones. En segundo término como variable la identificación de las prácticas comerciales y su eventual diferencias cognitivas asociadas a las diferencias de la práctica comercial, con ello se elabora la rejilla de lectura que permitió el establecimiento de las dos subpoblaciones base del estudio como son los carpinteros, los peluqueros panaderos.

En torno a la premisa de sí mismos de su status y del grupo al que pertenece de manera significativa existen los sentimientos de injusticia de su situación actual, es una imagen compartida en las tres profesiones, elemento anclado en fuertes elementos ideológicos y afectivos, crea un reforzamiento permanente de los factores de inmovilismo y amargura y un rechazo global e la sociedad actual y un repliegue en valores hipertradicionales de acuerdo al autor René.

El contexto juega un papel preponderante sobre la intensidad de las prácticas comerciales, las diferencias entre los sistemas de representaciones y conductas de los individuos, tienden a ajustarse a la intensidad de las diferencias de práctica aun guardando los mismos contenidos fundamentales.

El análisis de los resultados que derivan de la aplicación de 240 cuestionarios a una población de artesanos repartidos según tres oficios, dos niveles de dinamismo comercial y en el caso de la panadería como empresa, se verifica de manera esencial relativo a los lazos comportamientos/ representaciones para cada uno de los oficios, permitiendo una síntesis interpretativa, la cual inicia con los artesanos carpinteros quienes presentan una imagen bien y fuertemente estructurada en torno al núcleo como trabajador manual.

Presentando una imagen fragmentada $y$ polarizada contradiciendo la representación habitual de éste y jugando un papel preponderante en su representación la ganancia y la rentabilidad diferencial entre panaderos y carpinteros dinámicos y no dinámicos.

Las prácticas comerciales concretas de los artesanos se encuentran acompañadas de representaciones de ellos mismos y de su entorno sumamente concordante.

\section{References}

Jean-Claude, A. (2004). Filosofía y Cultura Contemporánea. México: Coyoacán S.A de C.V.

Piña Osorio, Juan Manuel, Cuevas Cajiga, Yazmín, La teoría de las representaciones sociales. Su uso en la investigación educativa en México. Perfiles Educativos [en línea] 2004, XXVI (tercera época) : [Fecha de consulta: 5 de septiembre de 2018] Disponible en: <http://www.redalyc.org/articulo.oa?id=13210605> ISSN 01852698 